\section{Essays into history}

\section{Christopher Cullen}

The Great Inertia: Scientific Stagnation in Traditional China.

By Wen-yuan Qian.

Croom Helm: 1984. Pp. 155. £15.95, \$24.

MR QIAN is a theoretical physicist who left the Peoples' Republic of China in 1980 after considerable personal suffering during the Cultural Revolution. $\mathrm{He}$ is now apparently a permanent exile in the United States, although his wife and daughter are still in China. He has changed disciplines as well as countries: in 1983 he completed an MA in history at Northwestern University, and he is now working for a PhD at the University of Michigan. As Qian himself makes plain, such personal details are not irrelevant to a judgement on his work.

Qian's book is conceived in the form of an attack on what he takes to be basic errors in the work of Joseph Needham. Most readers of this journal will have at least heard of Needham's huge pioneering study of pre-modern Chinese science, technology and medicine under the title Science and Civilisation in China, published by Cambridge University Press since 1954. (Seven volumes are planned in thirty tomes, of which eleven have so far appeared.) Qian mounts his attack in three essays which make up the bulk of his book. The first of these argues that the physical sciences in traditional China remained in a state of "stagnation". The second suggests that social factors such as the high degree of ideological control in China, ancient and modern, were responsible for the failure to develop modern science independently in the past, as well as for the failure to make adequate use of it in the present day. The final essay, written from the point of view of a thorough-going mechanicist reductionism, attacks Needham's view that the Whiteheadian organicism which he believes to be inherent in Chinese thought represents a possible way forward for modern science.

Qian's arguments are presented with clarity of expression and the polemical vigour which comes from deep personal involvement. $\mathrm{He}$ is passionately in earnest when he points to the factors which he believes have held back China in the past and continue to hold her back today, and the whole book is imbued with his sense of relief at being in an environment where he is free to speak his mind. I cannot however commend this short book as a significant contribution to scholarship. Qian's three essays try to settle some very broad issues in the history of science and society in East and West. For such attempts to be worth reading, it is essential for their author to base his generalizations on a solid foundation of first-hand knowledge of the full complexities of the historical evidence. Such an acquaintance usually induces a modest tentativeness in coming to conclusions. Qian however is cocksure and dogmatic throughout: all the important questions are simple and he has found the answers to them. Ironically, what he does know about Chinese science seems to have been drawn in its totality from a study of a few of Needham's published volumes. With disarming frankness (p. 19) Qian tells us that he wrote the second essay of his trio before commencing even this very partial exploration. Qian calls his technique of confident seat-of-the-pants generalization "macrohistory". I am afraid it reminds me of what Jonathan Swift called "the art of being deep learned and shallow read".

The root of Qian's problem is that he seems to believe that to be a modern Chinese trained in modern science is ample qualification for writing on the history of Chinese science and society over the past three thousand years. For comparison, how seriously would we take the work of a modern Greek theoretical physicist who published a rapid review of the cosmology of Aristotle? Qian is simply not going to make any impact on the audience he seeks to influence, which is presumably the small but growing group of scholars who study Chinese science from the original source material. His background may be some excuse for being out of touch, but there is no excuse for those who have encouraged him into such damagingly premature publication.

Christopher Cullen is a former Research Fellow of Clare Hall, Cambridge, and has published mainly in the field of ancient Chinese astronomy and mathematics. At present he is Head of Physics at Highgate School, London.

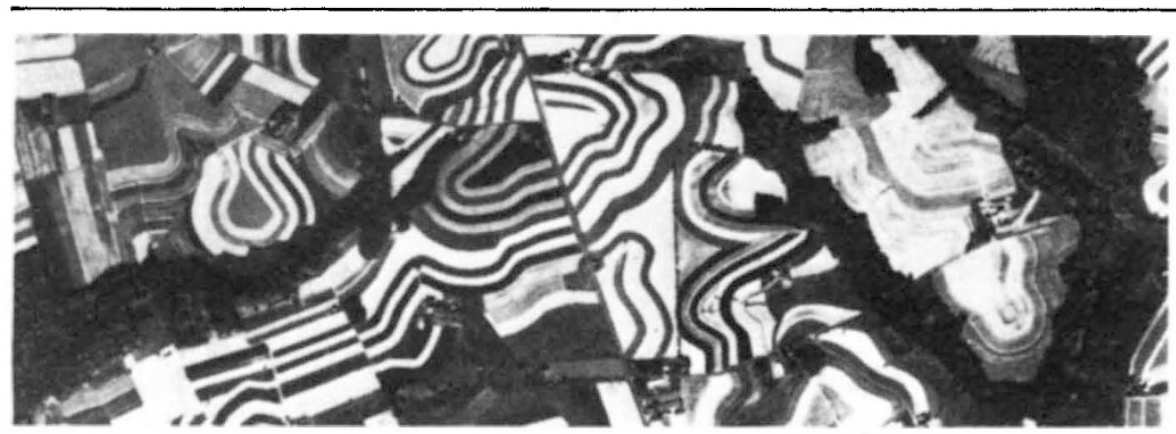

Patterns of agriculture - colour stripping of farmland in Lancaster County, Pennsylvania. The picture is reproduced from Landprints, by Walter Sullivan, recently published by Times Books New York (price \$22.50). The book will be reviewed in Nature at a later date. 